\title{
Stochastic modeling of well log data: Application in Massapê field, Recôncavo Basin, Bahia - Northeast Brazil

\author{
Rodrigo Dutra ${ }^{1}$, Mário Martins Ramos ${ }^{1}$, Rodrigo Bijani ${ }^{1}$ and Antonio Fernando Menezes Freire ${ }^{1}$ \\ 1 Universidade Federal Fluminense (UFF)
}

Copyright 2021, SBGf - Sociedade Brasileira de Geofísica.

This paper was prepared for presentation during the 17th International Congress of the Brazilian Geophysical Society, held in Rio de Janeiro, Brazil, 16 - 19 August, 2021.

Contents of this paper were reviewed by the Technical Committee of the 17th International Congress of The Brazilian Geophysical Society and do not necessarily represent any position of the SBGf, its officers or members. Electronic reproduction or storage of any part of this paper for commercial purposes without the written consent of the Brazilian Geophysical Society is prohibited.

\section{Abstract}

Well logging is a valuable process during the investigation of a subsurface's structure. Once the log data is accurately acquired and treated, it is possible to produce a reliable interpretation of the subsurface in depth, increasing the commercial production of oil and gas fields. However, logistical and technological complexity of the acquisition process may result in absent or unreliable data. Thus, covering such limitations with synthetic well log data can be considered an effective alternative. In this work we present a method based on statistical concepts to simulate well log data. First, a data set comprising several wells with interpreted lithologies is considered. At this stage, the data are separated by electrofacies, for each log in depth (e.g., density, gamma-ray, neutrons porosity and sonic logs). After that, a specific log of a particular well is set for simulation. Then, a vertical data windowing is defined by the user to determine some statistics (i.e., mean property values and standard deviation) in depth for each separated electrofacies. To set an ideal window size, we cross-correlate each log in depth. To validate the proposed methodology, controlled tests are performed for the modeled well 7MP-55D-BA, in the Massapê Field, Recôncavo Basin, Bahia. Due to perfect conditions, we decided to use density, neutrons and gamma-ray logs in this work. The comparison between real and simulated log data for the modeled well are made for two different window sizes (i.e., $100 \mathrm{~m}$ and $5 \mathrm{~m}$ ), showing an improved resolution when a small size is considered. Additionally, the major patterns in the real log data are accurately reproduced in the synthetic log data, which shows a very good performance of the proposed methodology. This work ends up with a simulation of sonic log, which is absent in the modeled well.

\section{Introduction}

The applied geophysics discipline plays a crucial hole in improving the geological knowledge of sedimentary basins through the acquisition, treatment, modeling, inversion and interpretation of geophysical data. To solve largescaled problems, such as the determination of basement reliefs, one needs regional geophysical data sets, such as potential-field data and seismic readings Kellogg (1953); Blakely (1996). For a more specific problem, drilling a well and collecting such a punctual data may be recommended (Kearey et al. 2009). Well logging concepts are based on acquisition tools in depth. The wide variety of equipment results in different geophysical logs, such as density (RHOB), resistivity (ILD), spontaneous potential $(\mathrm{SP})$, gamma rays (GR). Consequently, this large set of observations allows a detailed study of the subsurface, which is prolific for exploration of oil and gas (Ellis and Singer 2007; Dvorkin et al. 2014; Cannon 2015).

Despite well logging predominance in applied geophysics, due to the affinity between rock and readings, some logistical problems may affect the acquired measurements. Several technical failures (e.g, collapse of the well, damage and trapping of tools) often occur during the data acquisition, which promote the absence or corruption of the log data Asquith and Gibson, 1982; Ellis and Singer 2007; Kearey et al., 2009). To overcome such limiting aspects, several methodologies have been considered over the last few years. Recently, da Silva et al. (2015) proposed some empirical expressions to estimate sonic and density logs. With these synthetic data, the seismic data from Recôncavo basin can be used for improving the geological interpretation. Chagas et al. (2010) use multi-dimensional statistics to define an equation for sonic log as a function of other logs. Following the artificial intelligence guideline, Zhang et al. 2018) propose a recurrent neural network to estimate missing or incomplete logs. The advantage of this recursive approach lies in the efficiency of the method facing a small training data set.

With this work we propose a new methodology to simulate log data by fundamental statistical concepts, such as arithmetic mean, standard deviation, cross correlation and data windowing. First, the user chooses log data and well to be simulated, referred to as modeled well. After that, a data set comprising a specific number of neighboring wells are selected. This database is then separated into logs for each lithotype in depth. Then, to compute the statistics in a more refined approach, a moving window in depth is established by the user. To define an ideal size for the window, a vertical cross correlation using Pearson's coefficients is obtained. After computing the mean and the standard deviation within the moving window for each lithology, a Gaussian probability density function (pdf) is used to estimate the synthetic log. All log data used in this work is referred to Recôncavo basin, Bahia state, Northeast Brazil. 


\section{Geologic settings}

\section{Recôncavo Basin}

The Recôncavo Basin is mostly an onshore basin, located in the northeastern region of Brazil, in the state of Bahia, with an area around $11,500 \mathrm{~km}^{2}$. The structural configuration of this basin is related to the initial phase of super continent Gondwana's separation, causing the Atlantic ocean expansion (Silva et al., 2007). Figure 1 shows the boundaries of the basin.

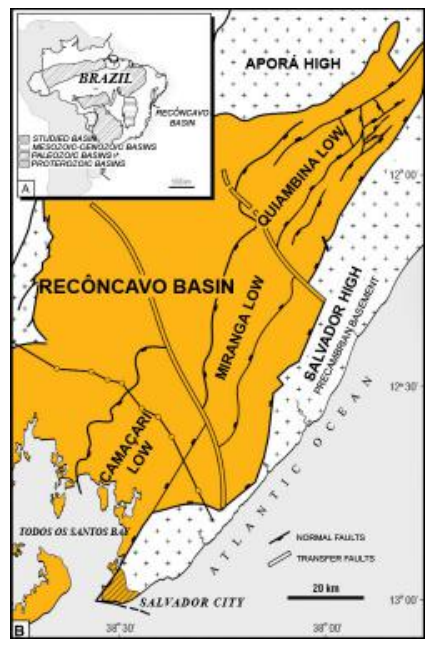

Figure 1: Location of Recôncavo basin (Bruhn, 1999).

\section{Massapê Field}

The study area comprises the Massapê field, with approximately $23.96 \mathrm{~km}^{2}$, located in the Recôncavo basin, in the state of Bahia, northeast Brazil. Figure 2 highlights the Massapê field location.
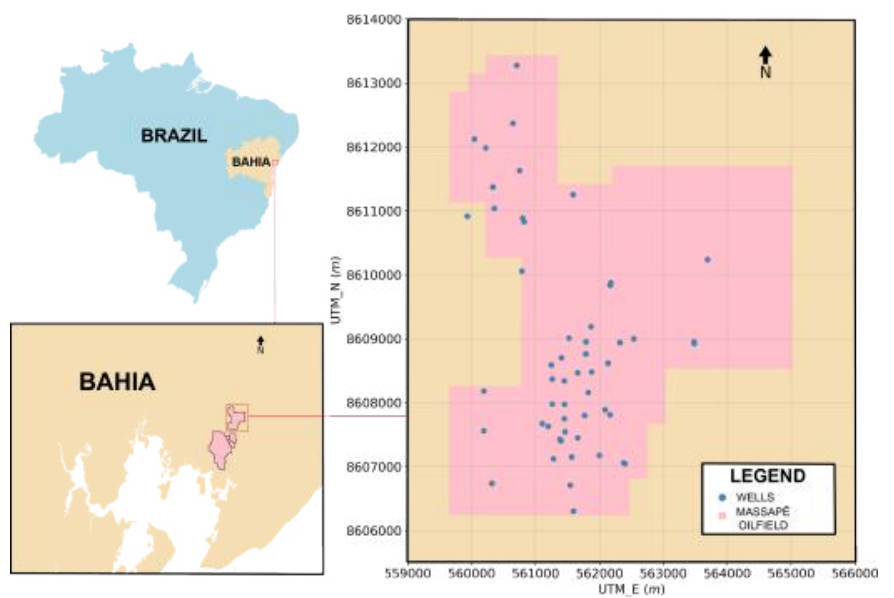

Figure 2: Location of Massapê field, in Recôncavo basin.

This field produces both oil and gas. The reservoir rocks are the sandstones of Maracangalha formation, Caruaçu member. This corresponds to $93 \%$ of the oil in place, the remaining are encountered in reservoirs of the Pojuca Formation and also in the sandstones of the Marfim formation (Magnavita 1995; Freire et al. 2020).
The reservoir zones of the Massapê field are divided into Caruaçu-1 (CRC-1), Caruaçu-2 (CRC-2) and Caruaçu3 (CRC-3). These zones are referred to as turbiditic systems and can also be further separated into 23 stages, depending on the different responses to certain geophysical profiles. The stages, and consequently, the turbiditic systems are basically formed by four electrofacies present in 56 exploration and development wells in the Massapê field, which are: sandstone, slurry, shale and siltstone (Freire et al. 2020).

\section{Methods}

Imagine, for example, that there is a specific well in which you only know the lithologies in depth. To be able to simulate some sort of log data, one needs to follow four basic stages, described in the next subsections.

\section{Definition of database}

Figure 3 shows all available wells at Massapê field. After setting the modeled well (e.g, red dot in Figure 3), the user should create a database, which is composed of several neighboring wells (e.g., blue dots in Figure 3. To compose an accurate database, lithologies and log data need to be known in advance.

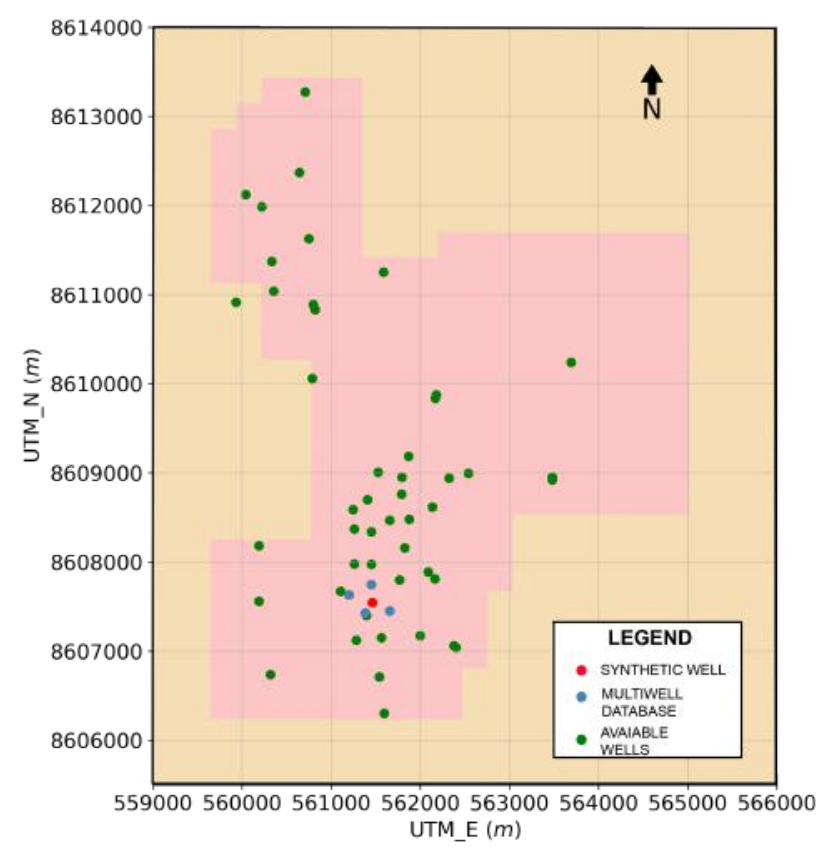

Figure 3: All wells in the Massapê field. The red dot locates the modeled well while the blue ones are related to the wells comprising the database.

\section{Log data separation in database}

At this stage, the log data comprising the database is separated for each interpreted lithology. This procedure is extremely important, once we need to compute some statistics are calculated in depth for each electrofacies. Figure 4 shows a simple sketch of the separation process. This scheme is repeated for all wells comprising the database. 


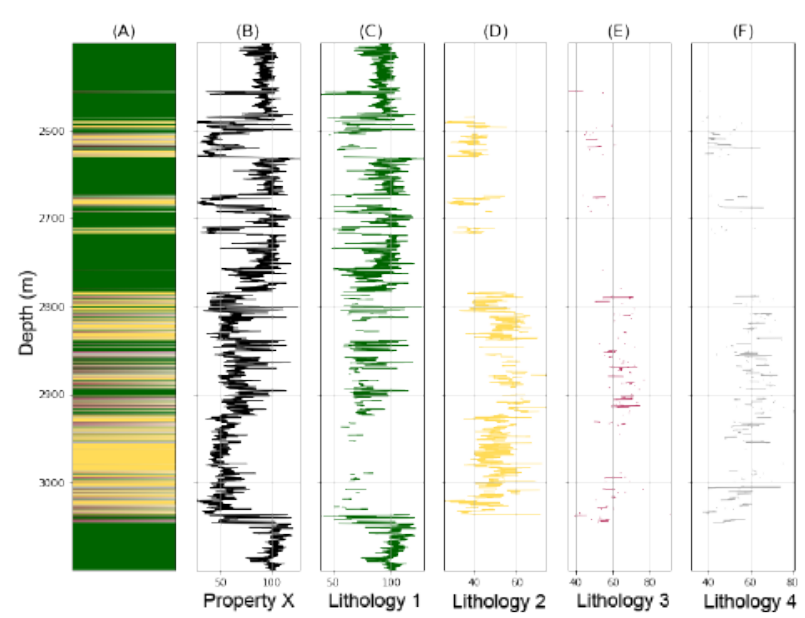

Figure 4: Separation of lithologies in depth. (A) a true lithologic log, (B) a specific log data to be considered. (C) Log data associated with (C) green, (D) yellow, (E) red and (F) grey lithology.

To perform the statistics for each well log data in depth, a vertical data window (VWS) is set by the user. Instead of testing several sizes, we decided to compute the cross correlation between the well log data and the depth. High cross correlation coefficient values endorse for an ideal VWS. Figure 5 shows the VWS procedure once the ideal size is defined.

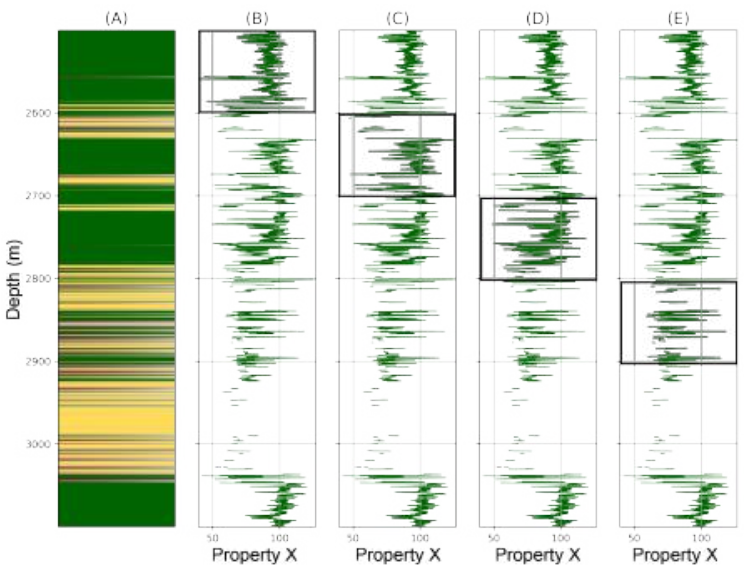

Figure 5: Data windowing procedure. (A) true interpreted electrofacies, (B) specific log data to be considered. The black rectangles indicate the window size and its variation in depth, without overlapping.

\section{Statistics}

The well log data is separated per lithology in depth for each window. This aspect allows the computation of means and standard deviations throughout the wells in the database, as can be seen in Figure 6 In all tests, we compute the statistical values per window and the normal probability density functions (pdfs) are defined to simulate the well log data.

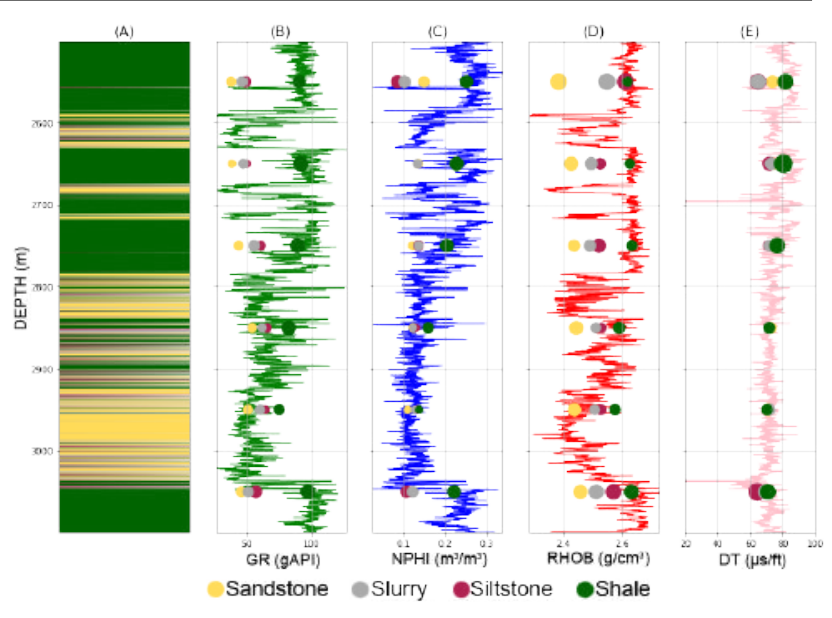

Figure 6: Sketch of the basic statistics. The colored circles are the means for each lithology. The size of the circles indicate the standard deviation.

\section{Results}

To validate the presented methodology, two simulations comprising different VWS are performed. A large one, referred herein as Large VWS (100 m depth interval) and a more refined one, referred herein as Refined VWS (5 m depth interval).

\section{Large VWS - 100 m depth interval}

Figure 7 shows the simulation for a very large window size. With this test, we intentionally bespeak how refined are the synthetic well log data produced by the proposed methodology. As expected, all three simulated curves (GR, $\mathrm{NPHI}$ and $\mathrm{RHOB}$ ) are not refined, once the window size is severely large (i.e., $100 \mathrm{~m}$ ). This aspect is due to a large standard deviation for each data value within the Large VWS. Despite, we can observe that some particular patterns in the true logs are reasonably well represented in the modeled logs, especially in Figure 7 (C) and (E).

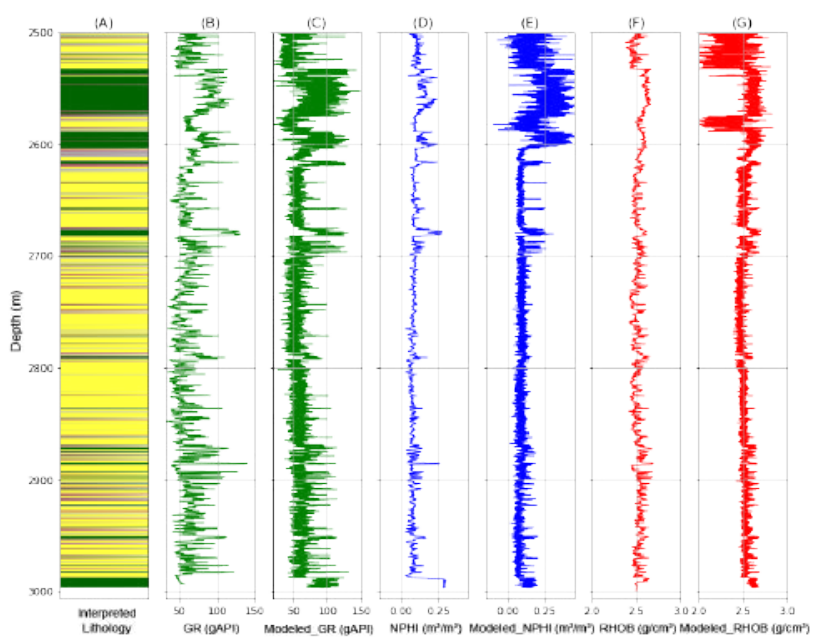

Figure 7: Results for a Large VWS. (A) True interpreted electrofacies, (B) True GR log, (C) Modeled GR log, (D) True NPHI log, (E) modeled NPHI log, (F) true RHOB log and $(G)$ modeled RHOB log. 
Figure 8 (A), (B) and (C) present crosslots of GR, NPHI and $\mathrm{RHOB}$ logs, respectively. These plots reinforce the high dispersion of each modeled log when compared with the true ones. Additionally, we can see that GR and NPHI logs do not present a reasonable fit. These analysis suggest a more refined VWS, which is presented in the next subsection.

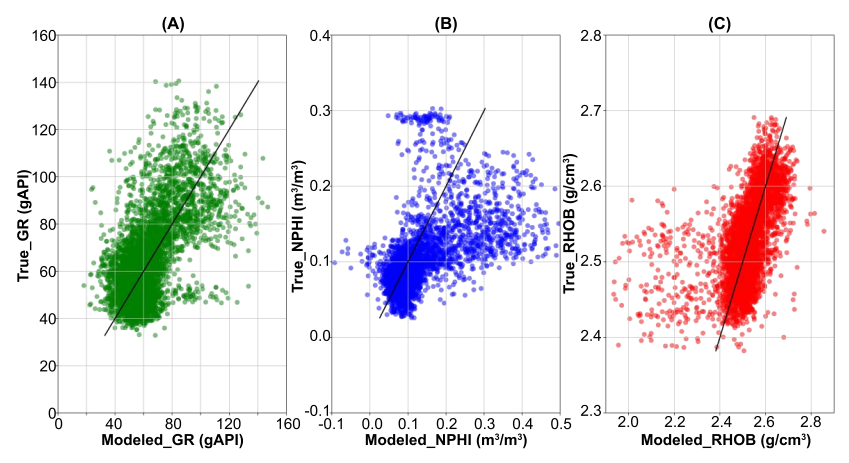

Figure 8: Scatter plots for (A) GR, (B) NPHI, (C) RHOB logs when the Large VWS is considered.

\section{Refined VWS - 5 m depth interval}

Figure 9 show both true and modeled well log data when a refined VWS is considered. We can see that the curves are more detailed and refined, showing the importance of accurately setting the vertical window size. Additionally, an extra track with a sonic (DT) log is also simulated, once this log is absent of this well.

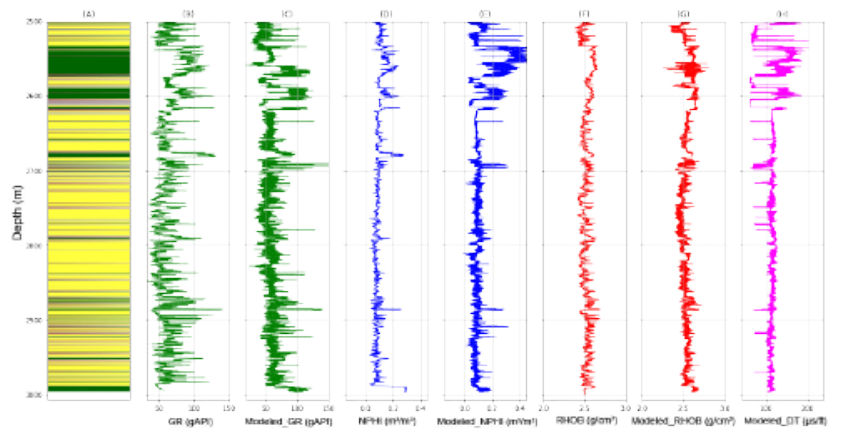

Figure 9: Results for a Refined VWS. (A) True interpreted electrofacies, (B) True GR log, (C) Modeled GR log, (D) True NPHI log, (E) modeled NPHI log, (F) true RHOB log, (G) modeled RHOB log and (H) simulated DT log.

We end up this test with a crossplot of GR, NPHI and RHOB logs for the refined VWS, as presented in Figure 10 (A), (B) and (C). The dispersion analysis shows a better fit for the RHOB log, while GR dispersion is quite the same for both tests. The simulated NPHI log presents some overestimated values, which might be related to the inconsistent log data around $2000 \mathrm{~m}$ depth in Figure 9 (E). We also observe that high standard deviation values in a specific window might be related to the presence of oil and/or gas. This aspect is relevant and need more investigations for improving this method. Additionally, caliper information are also crucial for defining a trustworthy log data for the definition of the database. In this work, we did not plot any caliper log, but all log data used in this work were pre-processed.

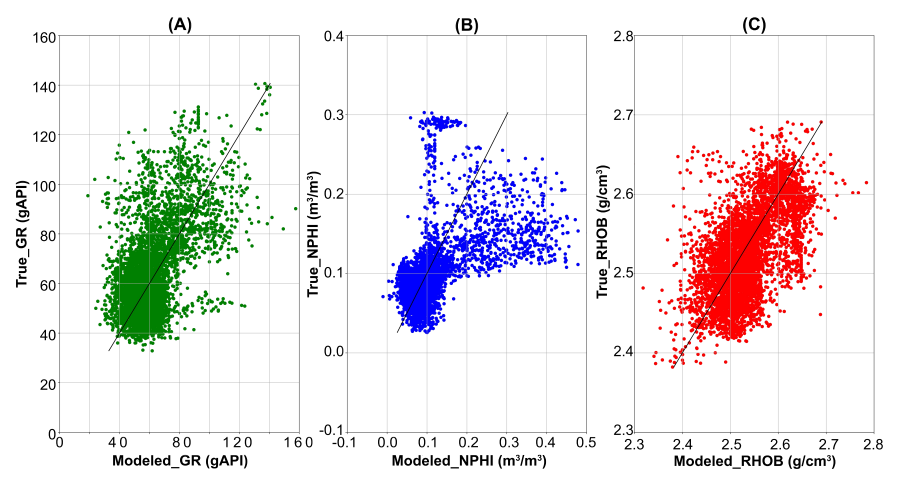

Figure 10: Scatter plots for (A) GR, (B) NPHI, (C) RHOB logs when the Refined VWS is considered.

\section{Conclusions}

The present work presents a new strategy for simulating well log data through a robust database and basic statistical concepts. A database comprising neighboring wells is required for simulations using different window sizes, according to high values of correlation coefficients. Tests using well 7-MP-55D-BA, referred as modeled well are performed for GR, NPHI and RHOB logs. Two window sizes, named Large (100 m depth interval) and Refined (5 $m$ depth interval) VWS are considered in the simulations. The first one presented disperse log curves, which is related to a severely large window. The simulations are improved when the window size is reduced for $5 \mathrm{~m}$ depth interval. Another relevant aspect lies in the knowledge of true interpreted electrofacies, otherwise the method will not simulate reliable logs curves. To reinforce the reasonable quality of the simulations presented in this work, crossplots for both window sizes are analyzed jointly with the logplots. As a final remark, we simulate a missing DT log for the well 7-MP-55D-BA, which could be considered a valuable contribution of this work, especially for missing or corrupted logs.

\section{Acknowledgments}

Authors would like to thank Petrobras for funding this research. We also appreciate all contributors to Python libraries, once this work was fully developed in this programming language. Authors are grateful to Carolina Ferreira and Thais Candido for precious help during the definition of interpreted electrofacies.

\section{References}

Asquith, G. B., and C. R. Gibson, 1982, Basic well log analysis for geologists: Amer Assn of Petroleum Geologists, 3.

Blakely, R. J., 1996, Potential theory in gravity and magnetic applications: Cambridge university press.

Bruhn, C. H. L., 1999, Reservoir Architecture of DeepLacustrine Sandstones from the Early Cretaceous Recôncavo Rift Basin, Brazil: AAPG Bulletin (American Association of Petroleum Geologists); (United States), $1502-1525$.

Cannon, S., 2015, Petrophysics: a practical guide: John 
Wiley \& Sons.

Chagas, E. S., S. Russo, and V. Simon, 2010, Geração de perfil sônico sintético em poços de petróleo através dos modelos de regressão não lineares usando a profundidade como variável regressora: Scientia Plena, 6.

da Silva, A. A. N., B. F. Bahia, T. C. S. Sant'ana, and M. Holz, 2015, Modelagem de perfis geofísicos sintéticos para possibilitar a amarração sísmica-poço na bacia do recôncavo: 14th International Congress of the Brazilian Geophysical Society \& EXPOGEF, Rio de Janeiro, Brazil, 3-6 August 2015, Brazilian Geophysical Society, 1121-1126.

Dvorkin, J., M. A. Gutierrez, and D. Grana, 2014, Seismic reflections of rock properties: Cambridge University Press.

Ellis, D. V., and J. M. Singer, 2007, Well logging for earth scientists: Springer, 692.

Freire, A. F. M., G. F. R. dos Santos, C. F. da Silva, and W. M. Lupinacci, 2020, Recognition of turbidite stages in the massapê oil field, recôncavo basin - brazil, using well logs: Journal of Petroleum Science and Engineering, 192, 107279.

Kearey, P., M. Brooks, and I. Hill, 2009, Geofísica de exploração: Tradução maria cristina moreira coelho: São Paulo, Oficina de Textos.

Kellogg, O. D., 1953, Foundations of potential theory: Courier Corporation, 31.

Magnavita, H. T. F. L. P., 1995, Rift border system: The interplay between tectonics and sedimentation in the reconcavo basin, northeastern brazil: AAPG Bulletin, 79 .

Silva, O. B., J. M. Caixeta, P. d. S. Milhomem, and M. D. Kosin, 2007, Bacia do recÃ'ncavo.

Zhang, D., C. Yuntian, and M. Jin, 2018, Synthetic well logs generation via recurrent neural networks: Petroleum Exploration and Development, 45, 629-639. 